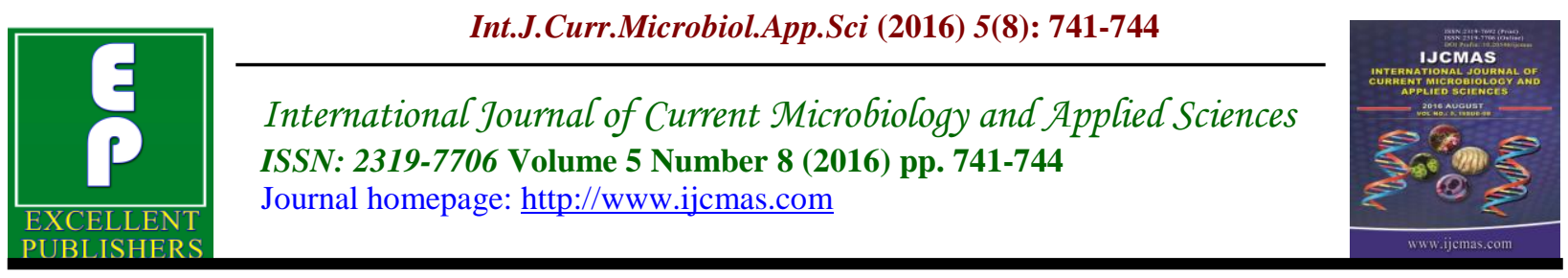

Original Research Article

http://dx.doi.org/10.20546/ijcmas.2016.508.083

\title{
Prevalence of Widal Positivity in Tertiary Care Hospital in North India
}

\author{
H. Lall*, M. Jais and R. Kaur \\ Department of Microbiology, LHMC, Delhi, India \\ *Corresponding author email id:
}

\begin{abstract}
A B S T R A C T
Keywords

Typhoid,

Widal,

Prevalence.

Article Info

Accepted:

28 June 2016

Available Online:

10 August 2016

This study was done to investigate the prevalence of widal positivity in a tertiary care hospital. i.e Lady Hardinge Medical college., New Delhi. The Study period was January 2015-December 2015. Blood samples were tested from patients attending OPD and in Wards and clinically suspected of typhoid fever. Widal test was performed on all blood samples suspected of typhoid fever. The widal test was done on all 2214 received blood samples from patients. The age of patients were in range of 0-65 years in both the sexes. It was found to be positive in 138 cases and $\mathrm{TH}$ in 189 cases, $\mathrm{AH}$ was found to be positive in 30 cases and $\mathrm{BH}$ in 12 cases. Widal test is the only practical test available for the diagnosis of enteric fever. The Widal Test is easy and inexpensive test which can be of diagnostic value when blood cultures are not available or feasible. The widal test is most useful diagnostic tool in typhoid fever till today.
\end{abstract}

\section{Introduction}

Typhoid fever is a systemic infection which is caused by the bacterium, Salmonella enteria, Serotype Typhi and is remains one of the major cause of morbidity and mortality. The Indian subcontinent is the hotspot of typhoid activity (Bijapur et al., 2014). The socioeconomic impact of the disease is huge, because the typhoid survivors may take several months to recover and to resume work.

An early and accurate diagnosis of typhoid fever is necessary for a prompt and effective treatment and to identify the individuals that may serve as a potential carrier, who may cause acute typhoid fever outbreaks (Andualem et al., 2014).
Blood, bone marrow culture and stool culture are the most reliable diagnostic methods. Culture is expensive techniques and some bacterial culture facilities are often unavailable (Elseed, 2015). In most countries, widal is widely used test in typhoid fever diagnosis because Widal test is relatively cheaper, easy to perform and requires minimum training and equipment.

Widal test is form of tube agglutination test which detects the IgM and IgG antibodies to salmonella typhi in the patient's serum from the second week of the onset of the symptoms of typhoid fever (Shanthi et al., 2012). The definitive diagnosis of typhoid fever requires the isolation of Salmonella typhi from the blood, feces, urine or other body fluids. 
In developing countries, facilities for isolation and culture are not available frequently, especially in smaller hospitals, and diagnosis totally relies up on the clinical features of the disease and detection of agglutinating antibodies to Salmonella typhi by the Widal test.

\section{Materials and Methods}

This study was conducted in the department of Microbiology, Lady Hardinge medical college, New Delhi. The Study period was Jan 2015-Dec 2015.

The Widal tube agglutination test was done on all sera collected from different departments from tertiary care hospital, using commercially available antigens (Tulip diagnostics). $0.4 \mathrm{ml}$ of two fold serially diluted patients sera (1:20 to $1: 320)$ in $0.9 \%$ normal saline were tested by adding an equal volume of antigen. A negative control was included in each batch of the test. The tubes were incubated at $37 \mathrm{C}$ for $24 \mathrm{~h}$ and then examined for agglutination (Park et al., 2014).

A diagnostic titre of 1:80 suggests positive reaction.

\section{Results and Discussion}

The Widal test was done in 2214 patients and TO was positive in 138 cases and TH was positive in 189 cases where as, $\mathrm{AH}$ was positive in 30 cases and $\mathrm{BH}$ was positive in 12 cases.

Percentage positivity of TO was found to be $6.2 \%$ and of $\mathrm{TH}$ was $8.53 \%$. Percentage positivity of $\mathrm{AH}$ was 1.35 and of $\mathrm{BH}$ was 0.54 respectively. Patients were ranges in age groups between 0-65 years .TO was highest in patients belonging to age group $11-20$ in both male (26 cases, $1.174 \%$ ) and female (60 cases, $2.71 \%$ ). TO was positive in 44 males (31.8\%) and 94 (68.1\%) females. $\mathrm{TH}$ was positive in $52(27.5 \%)$ males and 137(72.4\%) females. Both TO TH was found to be positive in 15 cases $(0.67 \%)$ only. $\mathrm{AH}$ and $\mathrm{BH}$ was found to be positive in $9(0.4 \%)$ cases only. All agglutinins were found to be positive in $2(0.09 \%)$ cases only. TH was also highest in age group 11-20 in both male (30 cases, $0.135 \%)$ and female $(70$ cases, $3.16 \%$ ) respectively. Agglutinins to S. typhi $8.53 \%$ were the most prevalent. Positive agglutinations for $\mathrm{AH}$ antigen were found to be less $(1.35 \%)$ and those for $\mathrm{BH}$ were found to be meager (only $0.54 \%)$.

The titre of $\mathrm{TO}$ and $\mathrm{TH}$ were highest in female gender. Majority of cases were noted during early summer and monsoons.

Typhoid fever is one of the major health problems in developing countries (Hemangi et al., 2014). Diagnosis of typhoid fever depends on isolation of salmonellae from blood, stool, urine, bone marrow, other body fluids. Emergence of MDR strains of Salmonella Typhi has only added burden of the disease (Kiran et al., 2015). Any delay in diagnosis of appropriate therapy only increase the risk of outcome (Begum et al., 2009). Our study focused on the utility of the widal test. In a developing country like India, Widal test has been used extensively in the serodiagnosis of typhoid fever. Fourfold rise of the antibody titre in paired sera are often is considered as diagnostic of typhoid fever (Kulkarni, 1994).

A paired sera is difficult to obtain and as a specific chemotherapy, it has to be instituted on the basis of a single widal test only. $\mathrm{R}$ syamlal et al., and Kulkarni et al., revealed that a single Widal test, in association with relevant clinical findings, can still be used as a useful diagnostic tool for typhoid fever (Kulkarni et al., 1994; Shanthi et al., 2012). Among the patients included in this 
study, $62.3 \%$ cases are in the range of age $11-20$ years followed by $29.7 \%$ in the age group of 21-30 years for TO and $52.9 \%$ for $\mathrm{TH}$ in age group 11-20 years and ,this may indicate that most Salmonella infections occur mainly in young adults. Which is similar to the study conducted by Elseed et $a l$., and Wain and Hosoglu et al., their study showed that incidence of enteric fever increase with the increasing age reaching its peak between 15-25 years old. Since the young adolescents are more infected in this study the reason could be the their more of outdoor/Junk food eating habits, that food may be handled by person shedding bacteria in their faeces, poor hygiene, lack of administration of booster doses. Careful food preparation and washing of hands are crucial to prevent typhoid. The serum of a proportion in any region contains antibodies capable of reacting to a variable titre in the widal test. In the absence of previous inoculation with typhoid or TAB vaccine, the frequency of $\mathrm{H}$ agglutinins in a population reflects its experience of Salmonella with the corresponding antigens either in the form of enteric fever or of latent infection therefore varies widely from country to country and from region to region.

The frequency and concentration of $\mathrm{O}$ agglutinins on the other hand, vary much less in different parts of the world. Hence, baseline surveys of the seroprevalence of S.Typhi $\mathrm{O}$ and $\mathrm{H}$ antibodies in the general population must be carried out as a guideline for interpretation of the Widal test.

Baseline surveys of the seroprevalence of $\mathrm{S}$ typhi $\mathrm{O}$ and $\mathrm{H}$ antibodies in the general population must be carried out as a guideline for the interpretation of the widal test.

Researchers must continue to search for the ideal rapid test to diagnose acute typhoid fever. Several urine assays have been developed but none has proved to upto the mark .More sophisticated molecular techniques for diagnosis such as PCR, are also being studied (Shanthi et al., 2012).

In conclusion, the widal test is an easy, cheap and relatively non invasive test that can be of diagnostic value in situation where blood culture is not feasible.

The diagnosis of typhoid fever on an early, single specimen is also of therapeutic value as early diagnosis is vital in typhoid, otherwise if the treatment is delayed it would result in fatal complications such as perforation or hemorrhage of the small bowel. Thus the test can be of diagnostic value in the early stage of the disease and thus help in reducing morbidity and mortality.

\section{References}

Cruickshank, R. et al. 1975. Medical Microbiology,Vol $2,12^{\text {th }} \quad$ edn. Edinburg, Churchill Livingstone, pp403-404.

Lateef, A.O. et al. 2000. Postgraduate Med. J., 76: 80-84.

Kulkarni, M.J., S.J. Rego. 1994. Indian J. Paediatrics, 31: 1373-76.

Shanthi, J. et al. 2012. Scholars Research library, Annals of Biol. Res., 3(4): 1847-1851.

Park, G. 2014. Int. J. Curr. Microbiol. Appl. Sci., 3(11): 708-710.

Bijapur, G., S. Kakkeri et al. 2014. A study to determine significant titre values of widal test in the diagnosis of enteric fever for a population of north Kerala, India. Al Ameen J. Med. Sci., 7(1): 7277.

Andualem, G., T. Abebe, N. Kebede. et al. A comparative study of Widal test 
with blood culture in the diagnosis of typhoid fever in febrile patients. $B M C$ Res., 7: 653.

Elseed, Y. 2015. Comparison between the widal test and culturing technique in the diagnosis of enteric fever in Khartoum State, Sudan. African $J$. Bacteriol. Res., vol7, p-56-59.

Wain, J., Hosoglu, S. 2008. The laboratory diagnosis of enteric fever. J. Infect. Dev. Ctries., 2: 421-425.

Hemangi, W., P. Shrikant. 2014. Endemic titer of Widal test in Kolhapur ,India.
Int J. Curr. Microbiol. Appl. Sci., 3(11): 708-710.

Kiran, Y., Y. Suresh. et al. 2015. A comparative study of thphidot and widal test for Rapid Diagnosis of Typhoid Fever. Int. J. Curr. Microbiol. Appl. Sci., 4(5): 34-38.

Begum, Z., H. Shamsuzzaman. et al. Evaluation of typhidot for early diagnosis of typhoid fever. Bangladesh J. Med. Microbiol., 3: 1013.

\section{How to cite this article:}

Lall, H., M. Jais and Kaur, R. 2016. Prevalence of Widal Positivity in Tertiary Care Hospital in North India. Int.J.Curr.Microbiol.App.Sci. 5(8): 741-744.

doi: http://dx.doi.org/10.20546/ijcmas.2016.508.083 